\title{
Development of Blood Donation Activities in Kyrgyzstan and General Implications for Blood Donation
}

\author{
Nurlanbek Kurmanaliev1, Baktygul Aisarieva'2, Iskenderbek Abdiraiimov1, \\ Zhainagul Abdirasulova ${ }^{3}$, Zhypargul Abdullaeva ${ }^{*}{ }^{\mathbb{D}}$, Mirlan Karataev ${ }^{1}$, \\ Nurzhigit Kurmanbaev', Majid Ali Khan ${ }^{5}$
}

\footnotetext{
${ }^{1}$ Department of Surgical Disciplines with Traumatology, Osh State University, International Medical Faculty, Osh, Kyrgyzstan ${ }^{2}$ Department of Hematology, Osh Interregional Clinical Hospital, Osh, Kyrgyzstan

${ }^{3}$ Department of Clinical Disciplines, Osh State University, International Medical Faculty, Osh, Kyrgyzstan

${ }^{4}$ Department of Anatomy, Histology and Normal Physiology, Osh State University, International Medical Faculty, Osh, Kyrgyzstan

${ }^{5}$ District Headquarters Hospital Gujranwala, Department of Anesthesia, Osh, Pakistan

Email: ${ }^{\star}$ jypar.science@oshsu.kg
}

How to cite this paper: Kurmanaliev, N., Aisarieva, B., Abdiraiimov, I., Abdirasulova, Z., Abdullaeva, Z., Karataev, M., Kurmanbaev, N. and Khan, M.A. (2020) Paper Title. Open Journal of Blood Diseases, 10, 101-109.

https://doi.org/10.4236/ojbd.2020.104012

Received: September 30, 2020

Accepted: December 4, 2020

Published: December 7, 2020

Copyright $\odot 2020$ by author(s) and Scientific Research Publishing Inc. This work is licensed under the Creative Commons Attribution International License (CC BY 4.0).

http://creativecommons.org/licenses/by/4.0/

\begin{abstract}
Objectives: This article is aiming to give an essential informative principle about the development of blood donation activities in Kyrgyzstan. Background: The sequence of blood donation procedure steps before donation, during donation, and after donation was shown and discussed. Methods/Materials: Rhesus factor determination in donors was achieved by "COLICO" method which is based on the use of monoclonal antibodies solution. Results: According to the blood donation activity of donors in Osh, Kyrgyzstan for the 2018 year, it was found that gratuitous donors who donated blood in 6 months were 269, in 9 months were 366, and in 1 year were 499 people. Relative donors who donated blood in 6 months were 3480, in 9 months were 5100, and in 1 year were 6701 people. Active donors donated blood in 6 months were 12, in 9 months were 14 and in 1 year were 17 people. Conclusion: No agglutination was observed in any of the plates for the first blood group; agglutination was observed with anti-A monoclonal antibody solution for the second blood group; agglutination was observed with anti-B monoclonal antibody solution for the third blood group; agglutination was observed with both of anti-A and anti-B monoclonal antibody solutions for the fourth blood group.
\end{abstract}

\section{Keywords}

Blood Donation, Donors, Plasmapheresis, Thrombocytapheresis, Blood Donation Activity 


\section{Introduction}

First-time donors indicated that they had experienced a reaction to blood donation, and donors who reacted were less likely to intend to return to donate [1]. One of the main requirements for donors is that blood donations from individuals found to have a positive direct antiglobulin test (PDAT) [2]. The decision for blood donation has been investigated around the world for decades to understand the blood donation process better, and to increase donation efficiency, safety, retention, collection numbers, and diversity of the donor pool [3]. Barriers and obstacles to blood donation among regular, lapsed blood donors and non-donors have been researched previously [4]. Most prevalent factors influencing blood collection process are fear of needles, general apprehension, negative feelings about the sight of blood, fear of adverse physiological reactions such as weakness or fatigue, dizziness, nausea, or fainting complicating the blood collection process, and are a significant disincentive for repeat donation [5]. Benefits and harms of blood donation were reported as after one blood donation total hemoglobin mass was reduced by about $8 \%-9 \%$ and to recover pre-donation values after 35 days on average [6]. Blood donor's suitability criteria based on science, medical opinion, and regulatory rules such as age, gender, hemoglobin deferral patterns [7].

A service quality scale for the blood donation was analyzed [8]. The blood donors associated with voluntary act of donation and care of patients were analyzed [9].

In Kyrgyzstan, not only the Kyrgyz citizens can be donors, but also foreign citizens who are legally residing and have appropriate registration can donate blood. There are strict requirements due to the lack of potential people who want to donate their blood. Limitations in this work were not healthy, overweight, donors younger than 18, and older than 60 years old. Selection of a donor based on compliance with the following criteria was shown in Figure 1.

Gender does not matter, but there are some restrictions, as a man without risk to health can donate blood up to 5 times in a year, and a woman only 4 times in a year. At the same time, the break between the next donations should not be less than 2 months. Types of blood donation can be classified into several kinds as it was represented in Table 1.

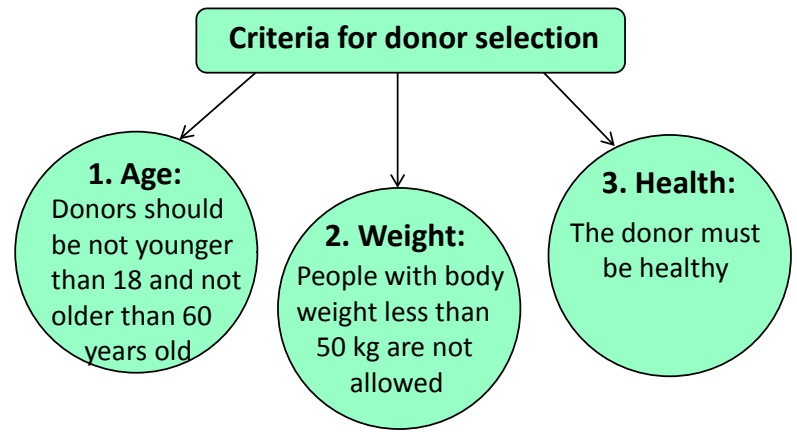

Figure 1. Criteria for donor selection. 
Table 1. Classification of blood donation recruitment and retention interventions (reproduced from reference [10] Makin et al. 2019).

\begin{tabular}{ll}
\hline Types of blood donation & Definition \\
\hline Motivational & Interventions aimed at increasing motivation toward blood donation \\
Cognitions-based & $\begin{array}{l}\text { Interventions targeting psychosocial cognitions related to motivation, } \\
\text { such as social nrms, attitudes, and barriers }\end{array}$ \\
Altruism & $\begin{array}{l}\text { Interventions using altruistic motives to motivate individuals to give } \\
\text { blood }\end{array}$ \\
Modeling & $\begin{array}{l}\text { Interventions showing another person giving blood to motivate } \\
\text { individuals to give blood }\end{array}$ \\
Reminders/asking & $\begin{array}{l}\text { Interventions using direct requests or reminders about the next } \\
\text { eligibility date and/or the next appointment to give blood (e.g., } \\
\text { telephone call prompt) } \\
\text { Incentives }\end{array}$ \\
$\begin{array}{l}\text { Interventions using incentives for donating blood such as a T-shirt, } \\
\text { money, prizes, tickets, and other }\end{array}$ \\
$\begin{array}{l}\text { Interventions to avoid dizziness and fainting, including applied muscle } \\
\text { tension during donation, pre-donation salt loading, on-site stomach } \\
\text { distension with liquids, donor distraction techniques, more stringent } \\
\text { estimated blood volume requirements for donors under age 23, salty } \\
\text { post-donation snacks, intensive education for individuals with higher } \\
\text { fear scores. }\end{array}$ \\
\hline reactions
\end{tabular}

\section{Study Design and Methods}

"COLICO" method used for blood Rhesus factor determination in donors. "COLICO" named after institute Central Order of Lenin Institute of Clinical Oncology where these solutions were invented and manufactured. This method has a high titer in the microplate 1:256, avidity of 60 seconds and do not give cross-reactions [11]. This method based on the use of monoclonal antibodies saline solution against antigens located on the surface of human red blood cells (RBCs). Monoclonal antibodies obtained by using certain strains of hybrid bacteria grown by genetic engineering. Monoclonal antibody solutions anti-A, anti-B, test tubes, plates for determining the blood group, sterile glass sticks (in a glass, Petri dish), isotonic sodium chloride solution, sterile pipette, and container with a $3 \%$ solution of chloramine were utilized. Place of donors' recruitment is a blood center in Osh; the period of study is covering 2018 year. Necessary stages of blood donation procedure in our study shown in Figure 2 and include the following steps: 1) Registration; 2) Medical checkup; 3) Calorie charge by donors before blood donation; 4) Blood donation; and 5) Inquiry point.

Types of the blood groups were determined according to these results: no agglutination was observed in any of the plates for the first blood group; agglutination was observed with anti-A monoclonal antibody solution for the second blood group; agglutination was observed with anti-B monoclonal antibody solution for the third blood group; agglutination was observed with both of anti-A and anti-B monoclonal antibody solutions for the fourth blood group. 


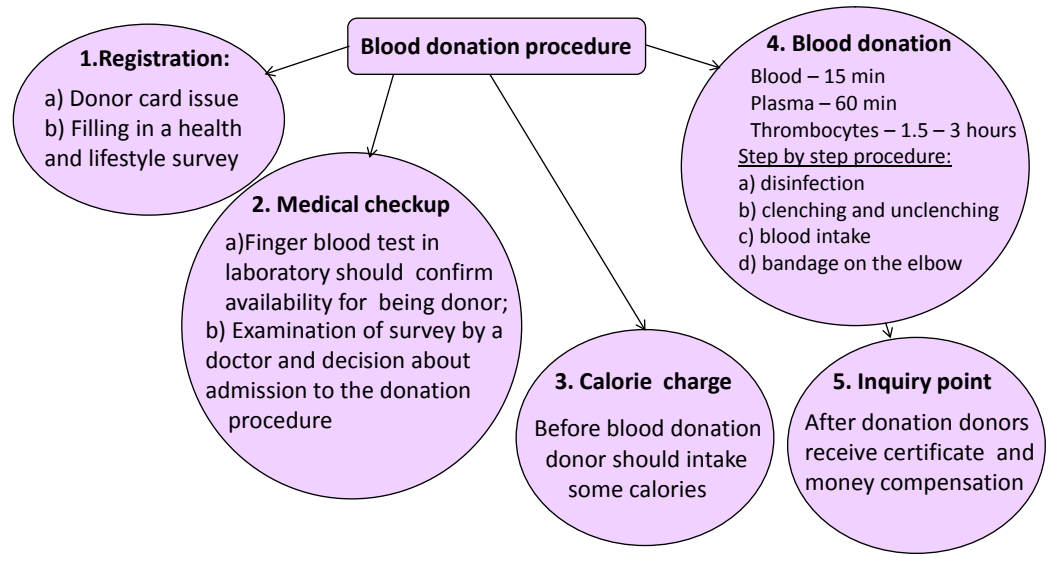

Figure 2. Steps of blood donation procedure.

\section{Results and Discussions}

It is better to avoid the use of protective equipment of healthcare providers, repeatable use of sticks, transfer sticks, and their contact with blood over a tray with clean sticks, disinfected items contact with blood. Minimal intervals between various kinds of blood donation by donors are shown in Figure 3. Such differences between the thrombocytopheresis, plasmapheresis and the whole blood donation are depending on the regeneration of blood components and plasma. After plasma donation, blood components separated from the plasma are returning to the donors organism directly. During the thrombocytes donation, all the blood components except thrombocytes are returning to the donors blood.

\subsection{Blood Components}

Essential blood products of human origin on the 2017 World Health Organization listed as following: blood and blood components (fresh-frozen plasma, platelets, red blood cells, and whole blood), immunologicals [12]. The major function of red blood cells (RBCs) is the transport of oxygen and minor functions are regulation of local blood flow and transport of carbon dioxide, while the function of neutrophils and monocytes are phagocytic cells participating in innate and adaptive immune responses [13].

\subsection{Plasmapheresis}

Plasma exchange (PE) or plasmapheresis can be defined as a therapy that involves the removal of a patient's plasma in exchange for exogenous fluid such as albumin [14]. Plasma exchange during blood donation lasted for about one hour. Plasmapheresis can be defined as blood plasma exchange, or therapeutic procedure in which whole blood is removed from the circulation, proteins such as antibodies and clotting factors filtered from the plasma, and then the whole filtered blood is returned to the circulation [15]. There are several types of plasmapheresis as shown in Figure 4. Blood plasma itself is a protein-rich solution 
in which white and red blood cells, platelets are suspended, and serum is the remaining fluid after removal of the clot from whole blood with the protein concentration in plasma/serum of $60-80 \mathrm{mg} / \mathrm{mL}$ from which $50 \%-60 \%$ are albumins and $40 \%$ globulins (10\% - 20\% IgG) [16].

Therapeutic plasma exchange is necessary for the management of autoimmune diseases: acute disseminated encephalomyelitis, polyradiculoneuropathy/Guillain-Barre syndrome, anemia, myasthenia gravis, vasculitis, etc. [20]. In TPE plasma is separated from the blood cellular (BC) components, discarded, and replaced with an isosmotic fluid containing commonly 5\% albumin to maintain the patient's oncotic pressure [21]. However, some complications of TPE exist such as bleeding, thrombosis, hydroelectrolytic disorders, hypertension, allergies, arrhythmias, and catheter-related infections including bacterial, mycobacterial, and viral infections [22].

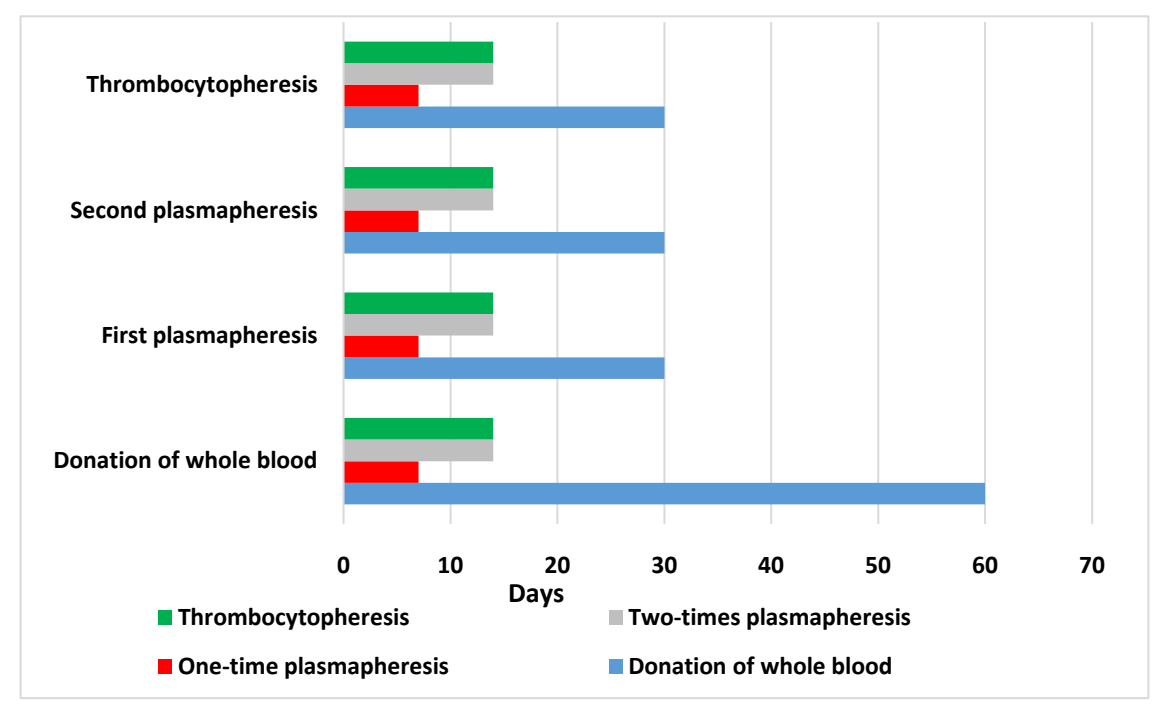

Figure 3. Minimal intervals between various kinds of blood donation and its components.

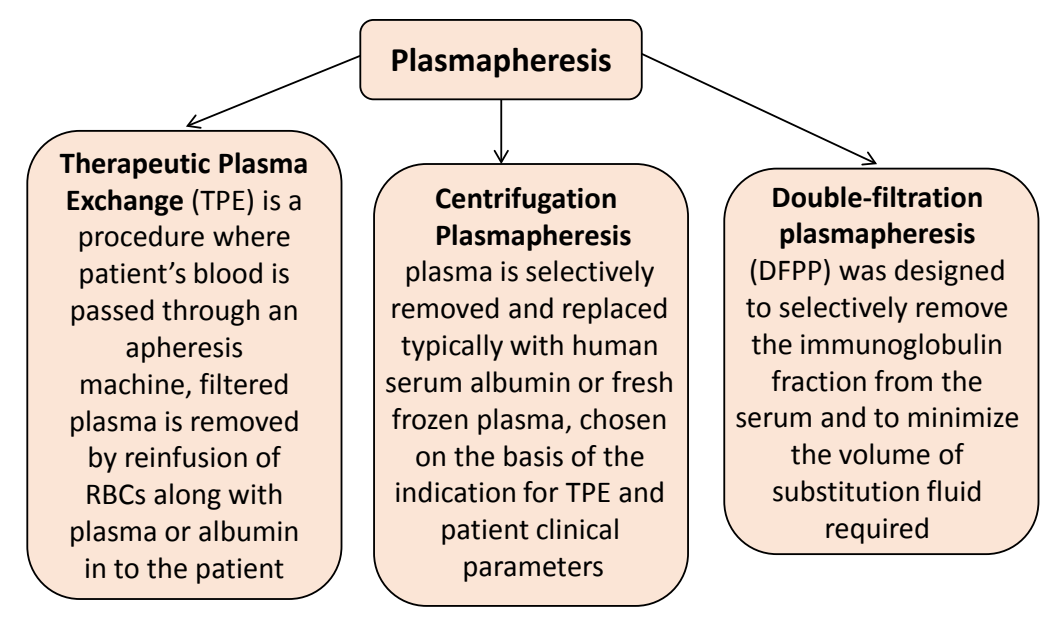

Figure 4. Types of plasmapheresis methods (adapted from references [14]-[20]). 


\subsection{Thrombocytapheresis}

Thrombocytapheresis is included in common therapeutic cytapheresis procedure which is based on the red blood cell (RBCs) exchange where intravascular volume is maintained by replacement of removed element with normal RBCs, crystalloids, or colloids [23]. In cases of extreme thrombocytosis, therapeutic thrombocytopheresis can be a useful procedure [24]. Therapeutic thrombocytapheresis involves the removal of platelets from patients with thrombocytosis, who have a platelet count of $>500,000 / \mu \mathrm{l}[25]$ (Shaz, 2009). Platelet depletion can be used in the treatment or prevention of complications from thrombocytosis in patients with hematologic malignancy, as 1.5 - 2 total blood volumes processed usually results in a $30 \%-60 \%$ platelet count reduction [26] (Simmons et al., 2019). The function of thrombocytapheresis is to reduce the platelet count rapidly during thrombocytosis and prevention of patients from having thrombotic events [27] (Das et al., 2013).

Blood donation activity in Osh, Kyrgyzstan for the 2018 year was determined as shown in Figure 5. Quantities of donors collected for a time span of 6 months, 9 months, and 1 year. Gratuitous donors, donors who were donated their blood to relatives, and active donors recruited for money compensation have participated in this survey.

Blood donation activity in Osh, Kyrgyzstan for the 2018 year was determined as shown in Figure 5. Quantities of donors collected for a time span of 6 months, 9 months, and 1 year. Gratuitous donors, donors who were donated their blood to relatives, and active donors recruited for money compensation have participated in this survey.

\section{Conclusion}

The main steps during blood donation procedures have been described. Donors were selected according to age, weight, and health criteria. Blood group types were determined according to these results: no agglutination was observed in any of the plates for the first blood group; agglutination was observed with anti-A

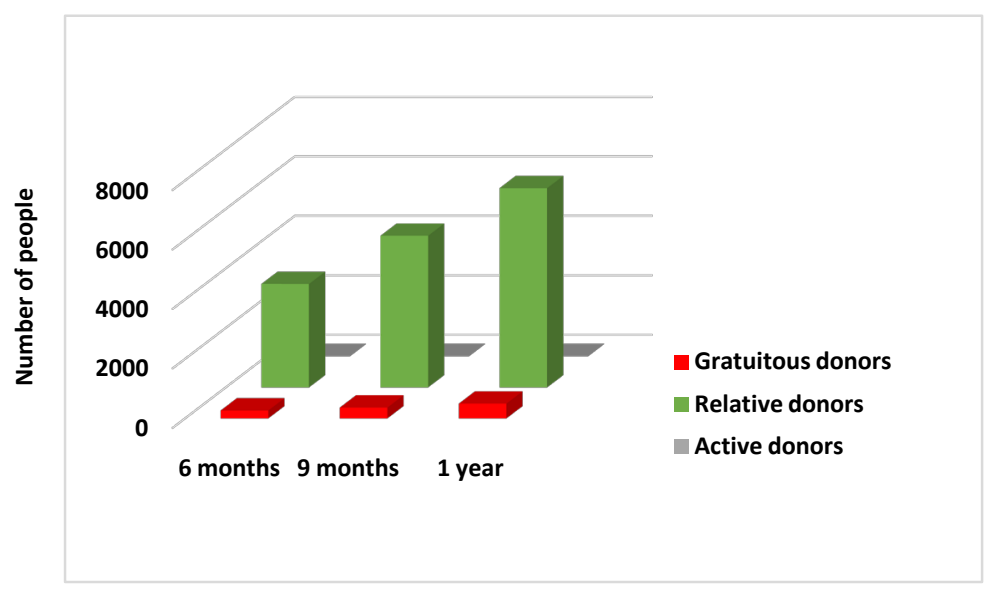

Figure 5. Blood donation activity of donors in Osh, Kyrgyzstan for the 2018 year. 
monoclonal antibody solution for the second blood group; agglutination was observed with anti-B monoclonal antibody solution for the third blood group; agglutination was observed with both of anti-A and anti-B monoclonal antibody solutions for the fourth blood group.

\section{Ethical Approval}

All procedures performed in studies involving human participants were following the ethical standards of the institutional and/or national research committee and with the 1964 Helsinki declaration and its later amendments or comparable ethical standards.

\section{Conflicts of Interest}

The authors declare no conflicts of interest regarding the publication of this paper.

\section{References}

[1] Masser, B.M., White, K.M. and Terry, D.J. (2013) Beliefs Underlying the Intention to Donate Again among First-Time Blood Donors Who Experience a Mild Adverse Event. Transfusion and Apheresis Science, 49, 278-284. https://doi.org/10.1016/j.transci.2013.06.008

[2] Hannon, J.L. (2012) Management of Blood Donors and Blood Donations From Individuals Found to Have a Positive Direct Antiglobulin Test. Transfusion Medicine Reviews, 26, 142-152. https://doi.org/10.1016/j.tmrv.2011.08.004

[3] Gillespie, T.W. and Hillyer, C.D. (2001) Blood Donors and Factors Impacting the Blood Donation Decision. Transfusion Medicine Reviews, 16, 115-130.

https://doi.org/10.1053/tmrv.2002.31461

[4] Charbonneau, J., Cloutier, M.-S. and Carrier, É. (2016) Why Do Blood Donors Lapse or Reduce Their Donation's Frequency? Transfusion Medicine Reviews, 30, 1-5. https://doi.org/10.1016/j.tmrv.2015.12.001

[5] Healy, J. and Murphy, M. (2017) Social Marketing: The Lifeblood of Blood Donation? In: Campbell C.L., Ed., The Customer Is Not Always Right? Marketing Orientations in a Dynamic Business World. Developments in Marketing Science: Proceedings of the Academy of Marketing Science, Springer, Cham, 811. https://doi.org/10.1007/978-3-319-50008-9_222

[6] Meurrens, J., Steiner, T., Ponette, J., Janssen, H.A., Ramaekers, M., Wehrlin, J.P., Vandekerckhove, P. and Deldicque, L. (2016) Effect of Repeated Whole Blood Donations on Aerobic Capacity and Hemoglobin Mass in Moderately Trained Male Subjects: A Randomized Controlled Trial. Sports Medicine-Open, 2, Article No. 43. https://doi.org/10.1186/s40798-016-0067-7

[7] Newman, B. (2001) Blood Donor Suitability and Allogeneic Whole Blood Donation. Transfusion Medicine Reviews, 15, 234-244. https://doi.org/10.1053/tmrv.2001.24593

[8] Melián-Alzola, L. and Martín-Santana, J.D. (2019) Service Quality in Blood Donation: Satisfaction, Trust and Loyalty. Service Business, 14, 101-129. https://doi.org/10.1007/s11628-019-00411-7

[9] Raivola, V., Snell, K., Helén, I. and Pertanen, J. (2019) Attitudes of Blood Donors to 
Their Sample and Data Donation for Biobanking. European Journal of Human Genetics, 27, 1659-1667. https://doi.org/10.1038/s41431-019-0434-1

[10] Makin, J.K., Francis, K.L., Polonsky, M.J. and Renzaho, A. (2019) Interventions to Increase Blood Donation among Ethnic/Racial Minorities: A Systematic Review. Journal of Environmental and Public Health, 2019, Article ID: 6810959. https://doi.org/10.1155/2019/6810959

[11] Uvaisova, A.S. (2012) Features of the Application of the Zoliklone Method for the Determination of Erythrocyte Antigens. Clinical Medicine of Kazakhstan, 2, 126-127.

[12] Samukange, W.T., Gardarsdottir, H., Leufkens, H.G.M. and Mantel-Teeuwise, A.K. (2019) Selection of Blood, Blood Components, and Blood Products as Essential Medicines in 105 Low- and Middle-Income Countries. Transfusion Medicine Reviews, 34, 94-100. https://doi.org/10.1016/j.tmrv.2019.10.005

[13] Bain, B.J. (2017) Structure and Function of Red and White Blood Cells. Medicine, 45, 187-193. https://doi.org/10.1016/j.mpmed.2017.01.011

[14] Hau, M.T.H., Shek-Kwan, C., On-Kei, C.A. and Lam, C. (2017) Effect of Plasmapheresis on Serum Levels of Clobazam, Levetiracetam and Topiramate. Epilepsy \& Behavior Case Reports, 8, 66-68. https://doi.org/10.1016/j.ebcr.2017.07.002

[15] Kang, P.B., Liew, W.K.M., Oskoui, M. and Vincent, A. (2015) Chapter 27: Juvenile and Neonatal Myasthenia Gravis. In: Basil, T., Darras, H., Royden, J., Ryan, M.M. and Darryl, C., Eds., De Vivo, Neuromuscular Disorders of Infancy, Childhood, and Adolescence, 2nd Edition, Academic Press, Cambridge, 482-496.

https://doi.org/10.1016/B978-0-12-417044-5.00027-5

[16] Leeman, M., Choi, J., Hansson, S., Storm, M.U. and Nilsson, L. (2018) Proteins and Antibodies in Serum, Plasma, and Whole Blood-Size Characterization Using Asymmetrical Flow Field-Flow Fractionation (AF4). Analytical and Bioanalytical Chemistry, 410, 4867-4873. https://doi.org/10.1007/s00216-018-1127-2

[17] Bobati, S.S. and Naik, K.R. (2017) Therapeutic Plasma Exchange-An Emerging Treatment Modality in Patients with Neurologic and Non-Neurologic Diseases. Journal of Clinical and Diagnostic Research, 11, EC35-EC37. https://doi.org/10.7860/JCDR/2017/27073.10480

[18] Hirano, R., Namazud, K., Suemitsu, J., Harashima, T. and Hirata, N. (2017) Plasma Separation Using a Membrane. Transfusion and Apheresis Science, 56, 649-653. https://doi.org/10.1016/j.transci.2017.08.008

[19] Puppe, B. and Kingdon, E.J. (2014) Membrane and Centrifugal Therapeutic Plasma Exchange: Practical Difficulties in Anticoagulating the Extracorporeal Circuit. Clinical Kidney Journal, 7, 201-205. https://doi.org/10.1093/ckj/sft163

[20] Tanabe, K. (2007) Double-Filtration Plasmapheresis. Transplantation, 84, S30-S32. https://doi.org/10.1097/01.tp.0000296103.34735.b8

[21] Ipe, T.S. and Marques, M.B. (2018) Vascular Access for Therapeutic Plasma Exchange. Transfusion, 58, 580-589.

https://doi.org/10.1111/trf.14479

[22] Aguirre-Valencia, D., Naranjo-Escobar, J., Posso-Osorio, I., Macía-Mejía, C., Nieto-Aristizábal, I., Barrera, T., Obando, M.A. and Tobón, G.J. (2019) Therapeutic Plasma Exchange as Management of Complicated Systemic Lupus Erythematosus and Other Autoimmune Diseases. Autoimmune Diseases, 2019, Article ID: 5350960. https://doi.org/10.1155/2019/5350960

[23] Becker, J.L. and Alcorn, K. (2001) Chapter 39: Therapeutic Cytapheresis: Red Blood Cell Exchange, Leukapheresis, and Thrombocytopheresis (Plateletpheresis). In: Hillyer, C.D., Hillyer, K.L., Strobl, F.J., Jefferies, L.C. and Silberstein, L.E., Eds., Hand- 
book of Transfusion Medicine, Academic Press, Cambridge, 333-341. https://doi.org/10.1016/B978-012348775-9/50090-9

[24] Almeida-Dias, R., Garrot, M. and Cid, J. (2019) Therapeutic Thrombocytapheresis for Extreme Thrombocytosis after Chemotherapy in Essential Thrombocytosis. Jour nal of Clinical Apheresis, 34, 503-506. https://doi.org/10.1002/jca.21683

[25] Shaz, B.H. (2009) Chapter 70: Therapeutic Thrombocytapheresis. In: Hillyer, C.D., Shaz, B.H., Zimring, J.C. and Abshire, T.C., Eds., Transfusion Medicine and Hemostasis, Academic Press, Cambridge, 403. https://doi.org/10.1016/B978-0-12-374432-6.00070-1

[26] Simmons, S.C., Schwartz, J. and Pham, H.P. (2019) Chapter 77: Therapeutic Thrombocytapheresis. In: Shaz, B.H., Hillyer, C.D. and Reyes Gil, M., Eds., Transfusion Medicine and Hemostasis, 3rd Edition, Elsevier Science, Amsterdam, 481-482. https://doi.org/10.1016/B978-0-12-813726-0.00077-5

[27] Das, S.S., Bhattacharya, S. and Sen, S. (2013) Managing Uncontrolled Postsplenectomy Reactive Thrombocytosis in Idiopathic Thrombocytopenic Purpura: Role of Thrombocytapheresis. Transfusion and Apheresis Science, 49, 171-173. https://doi.org/10.1016/j.transci.2012.09.009 